\title{
El perfil de la prensa de Rosario en tiempos de la Confederación
}

\author{
The press in Rosario \\ in times of the Confederation
}

\author{
Liliana Alicia Díaz \\ Universidad Nacional de Rosario \\ (Argentina) \\ ladz12@hotmail.com
}

\begin{abstract}
Resumen
El presente artículo examina el contenido de la prensa rosarina a mediados del siglo XIX en un contexto de profundos cambios políticos, económicos, sociales y culturales para analizar el perfil polémico de las formas discursivas que expresan la conflictiva coyuntura de la Confederación con el Estado de Buenos Aires y con la vecina República del Paraguay.
\end{abstract}

Palabras clave: Prensa rosarina - Opiniones - Intereses - Gobiernos y facciones.

\begin{abstract}
This article examines the contents of the press in Rosario in the mid-nineteenth century, in a context of profound political, economic, social and cultural changes. This approach enables a close analysis on s the conflicitve cojuncture of the Confederation, the State of Buenos Aires and the neighbouring Republic of Paraguay.
\end{abstract}

Key Words: Press - Rosario - Opinion - Interests - Governments and factions.

DÍAZ, Liliana, "El perfil de la prensa de Rosario en tiempos de la Confederación”, en Avances del Cesor, Año XI, No 11, segundo semestre 2014, pp. 41-57 


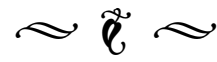

Las palabras escritas o habladas, sin exceptuar las más memorables, tienen su significado y alcance, no tanto por lo que son en si, cuanto por las circunstancias en que se pronuncian, por la predisposición de los oyentes...

\section{Bartolomé Mitre ${ }^{1}$}

\section{Introducción}

Después de Caseros y el derrumbe del régimen rosista continúa una etapa signada por un intenso antagonismo entre la Confederación Argentina y la provincia de Buenos Aires que concluye en 1861 con la Batalla de Pavón que da lugar a la reorganización del territorio bajo la égida porteña. Este período precisamente se caracteriza por la incompatibilidad de intereses entre ambas entidades estatales produciéndose conflictos cuyo reordenamiento y reformulación oscilan entre negociaciones y enfrentamientos armados como la Batalla de Cepeda cuando triunfan las fuerzas confederales y la mencionada Batalla de Pavón cuando las fuerzas porteñas logran imponerse. En esos años, el gobierno de Buenos Aires pone en funcionamiento un conjunto de disposi-

1. MITRE, Bartolomé, Comprobaciones Históricas, Editorial Librería la Facultad, Buenos Aires, 1916, p. 338. tivos simbólicos y prácticos en miras a lograr consenso político en la provincia ${ }^{2}$ y mantener su soberanía y autonomía dictando su propia constitución en 1854. En este marco, circulan los órganos de prensa que los diferentes grupos políticos crean para propagar sus ideas, ${ }^{3}$ difusión favorecida por la renovación de la sociabilidad urbana que se proyecta en la "explosión asociativa”. Ésta se instaura como un ámbito privilegiado de intercambio beneficiado por el aumento de población ${ }^{4}$ y del progreso generalizado.

Por entonces, la Confederación -integrada por trece provincias, teniendo como Director Provisorio a Justo José de Urquiza y como capital a Paraná- acuerda la formación de un Estado federal cuyas bases jurídicas se establecen en la Constitución Nacional de 1853. Este Estado, la Confederación, busca activar la economía de las provincias integrantes a través de los derechos de libre tránsito, la apertura y la reglamentación de los ríos interiores, reflejo del contenido de las Bases alberdianas. ${ }^{5}$

2. SÁBATO, Hilda, Historia de la Argentina 1852-1890, Editorial Siglo XXI, Buenos Aires, 2012, p 67.

3. Ídem, p. 29.

4. ALONSO, Paula (compiladora) Construcciones Impresas. Panfletos, diarios y revistas en la formación de los estados nacionales en América Latina, 1820-1920, Editorial Fondo de Cultura Económica, Buenos Aires, 2004, p.251

5. "Los ríos que no se navegan son como si no existieran. Hacerlos del dominio exclusivo de nuestras banderas indigentes y pobres, es tenerlos sin navegación... para que la mano inestable de nuestros gobiernos no derogue hoy lo que acordó ayer, firmad tratados perpetuos de libre navegación... si queréis que el comercio pueble nuestros desiertos, no matéis el tráfico con las aduana interiores... es un impuesto que debiera borrarse de las rentas sudamericanas. Es un impuesto que gravita sobre la civilización y el progreso" Juan Bautista Alberdi, Bases, Editorial Castellví S.A., Santa Fe, 1963, pp. 76-77. 
La ciudad de Rosario fortalece su lugar en la economía litoraleña por el impulso de modernización que la convierte en nodo portuario de la Confederación. En consonancia con profundos cambios que acarrea dicho proceso, se percibe una paulatina expansión de los ámbitos de sociabilidad, entablándose una particular relación entre el desarrollo histórico de la ciudad, la favorable coyuntura regional y el incremento de la sociabilidad urbana. Las prácticas relacionales acompañan a las transformaciones de la urbe asentada desde mediados del siglo XVIII en un pequeño espacio y cuyo origen "aparentemente mezquino" por carecer de la densa ritualidad que caracteriza los actos fundacionales del actual territorio argentino ${ }^{6}$ así como de una tradición colonial de conquistadores.

Las relaciones de sociabilidad pública en la incipiente ciudad son diversas y si bien la creciente vitalidad que las caracteriza no refleja "la naturaleza o la intensidad de las relaciones", ${ }^{7}$ determinados espacios de encuentro resultan propicios no sólo para la lectura de las últimas novedades sino además para que los sujetos sociales expongan y debatan sus ideas. La opinión pública revela su impronta tanto en la proliferación de manifiestos, folletos políticos, periódicos entre otros escritos que circulan, así como en las prácticas orales en lugares privados y públicos.

En el marco de esta perspectiva, el trabajo

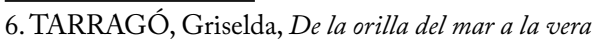
del rio: navegantes y comerciantes genoveses en el Plata y el Paraná (1820-1860), Ediciones Prehistoria, Rosario, 2011, p.133.

7. GONZÁLEZ BERNARDO, Pilar, Civilidad y politica en los orígenes de la nación argentina. Las sociabilidades en Buenos Aires, 1829-1862, Editorial Fondo de Cultura Económica, Buenos Aires, 2008, pp. 52-53. propone examinar el contenido de la prensa rosarina a mediados del siglo XIX para analizar las formas discursivas que, en tono polémico explícito o velado, reflejan la coyuntura conflictiva con la República del Paraguay y con el Estado de Buenos Aires. Se aprecia que la virulencia de las palabras que se vuelcan en la prensa forma parte de los mecanismos comunicacionales implementados por el gobierno confederal a través de la prensa local encaminados a difundir y legitimar las acciones de dicho gobierno.

El trabajo privilegia el aporte de aquellas propuestas recientes que con perspectivas innovadoras plantean el tema desde la historia política y cultural. ${ }^{8}$ En esta dirección, se entiende que el abordaje del diarismo, concepto propio de la época, permite reflexionar sobre las formas discursivas del siglo XIX y su relación con los aspectos sociopolíticos y el rol de la prensa en una sociedad republicana y civilizada. ${ }^{9}$ La vasta literatura sobre el tema enfatiza la función fundamental de los papeles periódi-

8. Entre otras propuestas: GOLDMAN, Noemí (editora) Lenguaje y revolución. Conceptos politicos clave en el Rio de la Plata, 1780-1850, Editorial Prometeo, Buenos Aires, 2008; LETTIERI, Alberto, La construcción de la República de la opinión, Buenos Aires frente al interior en la década de 1850, Editorial Prometeo, Buenos Aires, 2006; WASSERMAN, Fabio, "Notas sobre el diarismo en la prensa porteña de la década de 1850", en MUÑOZ, Marisa y VERMEREN, Patrice (compiladores) Repensando el Siglo $X I X$ desde América Latina y Francia. Homenaje al filósofo Arturo A. Roig, Editorial Colihue, Buenos Aires, 2009; WASSERMAN, Fabio, "La libertad de imprenta y sus límites: prensa y poder político en el Estado de Buenos Aires durante la década de 1850", en Revista Electrónica Almanack Brasiliense, Sao Pablo, No 10, Noviembre 2009, Disponible en: http://historiapolitica.com/datos/biblioteca/prensasix wasserman.pdf [Consulta: 15 de mayo 2010].

9. WASSERMAN, Fabio, “Notas sobre...”, Op. Cit., pp. 257-261. 
cos, especie de "ágora moderno", ${ }^{10}$ como medio formador de opinión y de propagación de los hechos que acontecen en el proceso de transformación de la vida pública, papeles que contrarrestan la acción de otros medios informales de transmisión de ideas, tales como el rumor, los pasquines y panfletos, que adquieren gran difusión durante la crisis de la monarquía española. ${ }^{11}$

Precisamente, el gobierno de la Confederación impulsa la formación de una red periodística como "estrategia de vinculación para la gestión de la prensa de distintas provincias" en miras de difundir y consolidar la política gubernamental. ${ }^{12}$ Esta sustentabilidad es posible en la medida que el gobierno de la Confederación posee suficientes recursos políticos y económicos. ${ }^{13}$ Los periódicos rosarinos integran esa trama extensa que permite reflexionar sobre los enunciados legitimadores- deslegitimadores como un ejercicio político que pretende influir en la opinión pública a favor o en contra de las políticas confederales y de los gobiernos paraguayo y porteño. Asimismo, es posible captar en sus páginas el grado de fluidez de la comunicación entre el gobierno y la sociedad sobre aquellas cuestiones de interés común.

10. PALTI, Elías, El tiempo de la política, el siglo XIX reconsiderado, Editorial Siglo Veintiuno, Buenos Aires, 2007, pp.166.

11. Ídem, p. 189.

12. MEGÍAS, Alicia, "Prensa y formación de la opinión pública. Rosario a mediados del siglo XIX", en Cuadernos del Ciesal, Rosario, 1996, Año 3, No 4, pp. 67-83.

13. HALPERÍN DONGHI, Tulio, José Hernández y sus mundos, Editorial Sudamericana, Buenos Aires, 1985, p. 24.

\section{La prensa en el espacio rioplatense}

Desde principios del siglo XIX los nuevos horizontes socio-políticos-culturales generados en Europa impulsan en el ámbito rioplatense la aparición de los primeros periódicos con la intención de dar a conocer a los súbditos las decisiones de los gobernantes. ${ }^{14} \mathrm{~A}$ partir de 1810 nuevos órganos de prensa ${ }^{15}$ agudizan el sentido de las voces escritas y avanzan sobre la libertad de publicación ${ }^{16}$ sin censura pero con un marco direccional en la formación de opinión pública orientado a la legitimación de las medidas que adoptan los gobiernos. ${ }^{17}$

Transcurridas dos décadas desde la Independencia y luego de transitar por una fracasada tentativa de organización unitaria y por enfrentamientos entre facciones que manifiestan tendencias contradictorias, coexisten prácticas que promueven la libertad de imprenta con aquellas que tratan de censurar las expresiones públicas. ${ }^{18}$ Particularmente durante el go-

14. El Telégrafo Mercantil, Rural Político e Histórico del Río de la Plata (1801-1802) dirigido por el español Francisco Antonio Cabella y Mesa, "El Semanario de Agricultura, Industria y Comercio" (1802-1807) fundado por Hipólito Vieytes y Pedro Cerviño y la Gazeta de Gobierno (1806-1810) periódico oficial, poco difundido $\mathrm{y}$ de series irregulares.

15. En marzo de 1810 se publica el primer número del Correo de Comercio redactado por Manuel Belgrano, órgano que se anticipa al que será meses más adelante el vocero de la revolución. La Primera Junta Gubernativa crea el periódico Gazeta de Buenos - Ayres

16. Los decretos del 20 de abril y 26 de octubre de 1811, establecen la libertad de imprenta en el Río de la Plata.

17. PALTI, Elías, El tiempo..., Op. Cit., pp. 101-102.

18. GOLDMAN, Noemí, "Legitimidad y deliberación: el concepto de opinión pública en Iberoamérica, 17501850", en Anuario de Historia de América Latina, Köln Weimar Wien, 2008, V. XXVIII, p. 232. 
bierno rosista se obstaculiza la locución plural siendo notable la disminución de la creación de periódicos en relación a períodos anteriores. ${ }^{19}$ Sin embargo, durante la primera mitad del siglo XIX, un balance sobre las impresiones periodísticas en el ámbito rioplatense señala la expansión de la prensa porteña en comparación con el resto de las provincias. Mientras en Buenos Aires se publican doscientos veinticinco periódicos y en la docta Córdoba treinta y cinco, las provincias del interior tienen que esperar hasta después de 1850 para tener sus primeras publicaciones, ${ }^{20}$ no sin sortear diversas dificultades. Efectivamente, en el período de la Confederación urquicista, la prensa periódica está condicionada por las estrechas fronteras de su público y el impedimento de particulares para costear las impresiones con ventas, exiguas suscripciones y aranceles por la publicación de avisos dirigidos a ese público pequeño. ${ }^{21}$ Asimismo, la situación de la prensa en las provincias interiores es desigual, tanto porque debían resolver cuestiones políticas, económicas y materiales -como la disponibilidad de las imprentas- así como problemas de distancias y comunicaciones en una geografía extensa. ${ }^{22}$ Por estas cuestiones, en tiempos de la Confederación, la producción periodística está lejos de ser un emprendimiento rentable. La empresa periodística, la periodización de las publicaciones y la distribución gratuita de ejemplares son posibles por el financiamiento del gobierno confederal, ya sea por suscripciones, por la compra de espacio para publicación

19. GONZALEZ BERNALDO, Pilar, Civilidad y

politica..., Op. Cit., p. 224

20. Ídem, p. 172.

21. HALPERÍN DONGHI, Tulio, José Hernández..., Op.Cit., p.23.

22. MEGÍAS, Alicia, “Prensa y formación...”, Op. Cit., pp. 67-68. de avisos del gobierno, por el préstamo de imprenta oficiales $\mathrm{u}$ otras formas de subvenciones. $^{23}$

Los recursos y la posibilidad de contar con un grupo cercano al gobierno y competentes en la actividad periodística aún sin una formación sistemática, son clave para el desarrollo de los emprendimientos editoriales. Estos voceros oficiales, sostenidos "a través de la concesión de cargos públicos o del otorgamiento de subsidios personales y oficiales", ${ }^{24}$ lejos de hacer de la imparcialidad en la comunicación de noticias su "profesión de fe", hacen política con la pluma ${ }^{25}$ dirigida a la opinión pública, enunciación frecuente en los periódicos de la época.

Para explorar el origen moderno del término opinión pública hay que sumergirse en la segunda mitad del siglo XVIII del viejo continente cuando irrumpe esa "fuerza políticamente operativa" en el vocabulario de las principales lenguas. ${ }^{26} \mathrm{~A}$ grandes rasgos, la opinión a modo de un tribunal social e instituido como lugar de la verdad, que censura o aprueba conductas individuales pierde su aura eclesiástica o cortesana y adquiere de manera incipiente la impronta política de los tiempos modernos. ${ }^{27}$

23. AUZA, Néstor Tomas, El periodismo de la Confederación 1852-1861, Editorial Eudeba, Buenos Aires, 1978, p. 17.

24. MEGÍAS, Alicia, “Prensa y formación...”, Op. Cit., p. 74 .

25. ALONSO, Paula, Construcciones impresas...,Op. Cit., p. 8 .

26. FERNANDEZ SEBASTIÁN, Javier, “Opinión pública" en FERNANDEZ SEBASTIÁN, Javier y FUENTES, Juan Francisco (directores) Diccionario politico y social del siglo XIX español, Editorial Alianza, Madrid, 2002, p. 477.

27. La abundante literatura sobre el tema queda fuera de este examen. 
Puede argüirse que la antigua acepción tardo romana vox populi, la teoría medieval del consentimiento y hasta la voluntad general de Rousseau preceden al concepto, sin embargo no alcanzan su pleno sentido. ${ }^{28}$

En Hispanoamericana, a partir de los procesos independentistas, el lenguaje político- jurídico empieza a incorporar un concepto de opinión pública que suplanta al magisterio moral del clero y que comienza a asentarse en una "historia semántica previa que la vincula al progreso de la Ilustración en Europa, a la libertad de imprenta, a la soberanía popular y a la representación política”. ${ }^{29}$ Las condiciones que hacen posible esta opinión pública no son sólo su difusión entre el público sino además su pertenencia a la res publica, esto es, una opinión expuesta a la información sobre las cosas públicas. La opinión se articula con los espacios públicos como lugares de reunión concretos de la ciudad, esfera por excelencia de la política. ${ }^{30}$ Este nuevo modo de vida asociativa voluntaria se desarrolla en espacios de confluencia o debate: los clubes, los cafés, los espacios urbanos y otros centros de sociabilidad como las logias masónicas. En este punto, cabe señalar la relevancia que alcanza la libertad de opinar en los mitines, las asambleas y los congresos constituyentes.

Las nuevas instituciones, aún con diferente

28. SARTORI, Giovanni, Teoría de la democracia. El debate contemporáneo, Editorial Alianza, España, 1988, T. I, pp. 117-118.

29. GOLDMAN, Noemí, PASINO, Alejandra, "Opinión Pública” en GOLDMAN, Noemí (editora) Lenguaje y revolución...,Op. Cit, p. 101.

30. GUERRA, François-Xavier, LEMPÉRIÈRE, Annick, Los espacios públicos en Iberoamérica. Ambigüedades y problemas. Siglos XVIII-XIX, Editorial Fondo de Cultura, México, 1998, p. 10.

46 composición pública y orientación, tienden a la praxis de la libertad de discusión y de crítica sobre temas relevantes entre personas privadas sin limitaciones políticas o religiosas. En este sentido, la liberación de la minoría de edad según la concepción ilustrada, implica para el individuo una mayor subjetividad y la posibilidad de pensar por sí mismo que parece coincidir con el pensar en voz alta. ${ }^{31}$

Sin embargo, en el ámbito rioplatense el surgimiento de la opinión y los espacios de sociabilidad reconstituye una nueva jerarquía. ${ }^{32}$ La libertad de opinar dista de identificarse con valoraciones cualitativas expresadas por el conjunto social y armoniza más con las estrategias y modos de articular las relaciones entre sociedad y Estado aplicados por el poder político vigente que trata de "fijar la opinión". Particularmente durante el gobierno rosista, ciertos aspectos relacionados con la opinión pública se constituyen en expresiones legitimadoras de su poder. Posteriormente, con el intento de homogeneización política para lograr la estabilización del régimen, aquellas manifestaciones que desacuerdan con la gestión, son motivos de rencillas y réplicas contundentes que pueden continuar con la censura o la represión. Algunas publicaciones, como el Archivo Americano $^{33}$ y La Organización ${ }^{34}$ buscan recortar sustancialmente la difusión de opiniones an-

31. HABERMAS, Jürgen, Historia y crítica de la opinión pública. La transformación estructural de la vida pública, Editorial Gustavo Pili, Barcelona, 2009, pp.137-138.

32. GUERRA, François-Xavier, LEMPÉRIÈRE Annick, Los espacios..., Op. Cit., p.17.

33. El Archivo Americano y Espiritu de la Prensa del Mundo, periódico oficial de Rosas publicado en inglés, italiano y español. Cuyo redactor es Pedro de Angelis (1784-1859).

34. La Organización de Entre Ríos es el periódico editado por Justo José de Urquiza. 
tagónicas reflejando con mayor intensidad la fuerte impronta facciosa que caracteriza el período por la pugna de grupos políticos armados. En este sentido, Domingo Faustino Sarmiento opina que el contenido de los periódicos rosistas y urquicistas deriva no de la opinión pública sino de la opinión privada de cada uno de sus respectivos redactores. ${ }^{35}$

\section{La prensa y la opinión pública en el ámbito rosarino}

La Capilla del Rosario, pequeño núcleo urbano ubicado en el Pago de los Arroyos que a principios de siglo era sólo una aldea, es declarada ciudad en 1852. Por entonces adquiere importancia en la medida que se configura como tal, en un contexto de nuevas condiciones políticas y económicas surgidas a partir de Caseros. La ubicación ribereña y nexo de caminos terrestres, más las decisiones del gobierno urquicista, favorecen el paulatino incremento del tráfico mercantil, determinan el perfil portuario de la Confederación y contribuyen a las mejoras generales de la ciudad que se transforma y por entonces, "por todas partes no se oye sino el ruido de la cuchara que levanta paredes, para hospedar a la numerosa población que afluye en busca de provechos". ${ }^{36}$

La apertura del río Paraná a la navegación de ultramar, con ello el incremento de la actividad portuaria y los correspondientes recursos aduaneros son ejes de conflictos permanentes con los intereses porteños. Las políticas rosistas sobre la navegación de los ríos interiores

35. SARMIENTO, Domingo Faustino, "Argirópolis", en Obras Escogidas, T. VII, Editorial Librería La Facultad, Buenos Aires, 1917, pp. 164-169.

36. La Confederación, No 30, Rosario, 03/06/1854, p. 3. tienen como efecto obturar el desarrollo del puerto. En particular, el bloqueo anglo-francés en 1843 condujo a Rosas a cerrar el río Paraná para impedir que las flotas extranjeras remonten sus aguas. Por tal motivo en esos tiempos, Rosario se convierte en "un lugar de concentración de tropas que vigilan el río" ${ }^{37}$ que, aunque apostadas sobre el arroyo Saladillo, no pueden impedir el contrabando y el intercambio directo con Montevideo.

La pujante actividad que se produce a partir del gobierno urquicista abre el camino para la llegada de periódicos de la región y de países vecinos, con ello la circulación de noticias. Esta red de contactos se entreteje con la recepción de libros y correspondencias tanto oficiales como particulares, entre otros papeles que circulan, y permite el conocimiento de las novedades del mundo y dinamiza la comunicación citadina y de la región. La actualización permanente cobra particular importancia entre los propietarios, comerciantes e integrantes del poder político que pretenden seguir el ritmo de los cambios vinculados con el proceso de modernización y con las transformaciones de las coyunturas regionales. Actualización requerida

para servir de alimento al progreso de aquel pueblo, núcleo del comercio de las Provincias del Interior, la prensa en el Rosario está destinada á tomar pronto grandes proporciones, y á ejercer una influencia benéfica en toda la República. ${ }^{38}$

Los espacios de sociabilidad pública en Rosario se despliegan al ritmo del clima ex-

37. ALVAREZ, Juan, Historia de Rosario (1689-1939), Editorial UNR, Rosario, 1998, p. 242.

38. La Confederación, No 30, Rosario..., Op.Cit., p. 3. 
pansivo y de las transformaciones urbanas. La nueva estructura de la ciudad, los ejes de circulación y los puntos de reunión favorables para la circulación de novedades, son elementos que organizan dicho espacio. ${ }^{39}$ En suma, el pasaje a la condición de ciudad altera la fisonomía de aquella población estructurada en torno a una sociabilidad familiar y paulatinamente surgen otros lugares de reuniones y comunicaciones. Particularmente, el jefe político progresista Nicasio Oroño ${ }^{40}$ impulsa los cambios que se materializan en la construcción del primer teatro; ${ }^{41}$ la apertura del coliseo La Esperanza ${ }^{42}$ -ambos sirven para conciertos, bailes y conferencias-; la apertura de dos hoteles ${ }^{43}$ uno de ellos La Rosa donde habitualmente se alojan viajeros extranjeros; el Club Mercantil; dos

39. GONZÁLEZ BERNARDO, Pilar, Civilidad y politica..., Op. Cit., p. 65.

40. Benjamín Virasoro, Nicasio Oroño, Jacinto Corvalán, Pascual Rosas, Agustín Fernández, Dalmacio Centeno, Ignacio Comas, Domingo Palacios se desempeñan como jefes políticos entre 1854 y 1858, año de creación de la Municipalidad.

41. El teatro comienza a construirse en forma provisional en junio de 1854, con el aporte de algunos vecinos y amigos del "fomento de las artes" en Periódico La Confederación, No 6, Rosario, 14/06/1854, p. 3. Las funciones se publican en los sucesivos números del periódico.

42. Si bien el coliseo La Esperanza funciona con anterioridad, se estrena pintado y decorado el 21/06/1857. CARRASCO Eudoro y CARRASCO Gabriel, Anales de la ciudad del Rosario de Santa Fé, Editorial J. Peuser, Buenos Aires, 1897, p. 359.

43. Hotel de las Naciones, cuya publicidad se puede leer en La Confederación, No 10, Rosario, 28/06/1854; y el Hotel Argentino inaugurado en 1858 según el periódico citado, No 599 del 22/07/1858. cafés ${ }^{44}$ y una librería, la Fama ${ }^{45}$ en cuyo local ubicado frente a la Plaza 25 de Mayo donde no sólo se pueden adquirir libros ${ }^{46}$ sino también artículos variados: papel carta, plumas, lapiceras, espejos, carteras, naipes, cigarrillos. ${ }^{47}$ A la primera Sociedad de Beneficencia Francesa continúa la organización de otra sociedad de la misma índole impulsada por Federico de la Barra, cuya primera presidenta es, a su vez, fundadora del Hospital de Caridad. Asimismo, las tertulias oficiales que se organizan en casas privadas para la recepción de funcionarios y personajes extranjeros que, por distintos motivos arriban a la ciudad, realzan las prácticas de sociabilidad de la incipiente elite. La recepción a jefes y oficiales de la escuadra brasileña, ${ }^{48}$ la bienvenida que "el Sr. Gefe Político, Sr. Oroño, dio personalmente... al distinguido buésped" Almirante Ferreira de Oliveira en los salones del Sr. Peñaloza, ${ }^{49}$ la recepción al Sr. Hopkins y su

44. El Café de Peyrano es el más antiguo fundado por Manuel Peyrano. En el patio central se organizan bailes y espectáculos públicos. CARRASCO Eudoro y CARRASCO Gabriel, Anales de la..., Op. Cit. p. 342.

45. ALVAREZ, Juan, Historia de Rosario..., Op. Cit., pp. 265-269.

46. En sucesivos números de La Confederación se anuncian para venta libros de contenido variado tales como Aforismos de Hipócrates, Arte de criar ganado, Buenos Aires y las provincias del Río de la Plata de Sir W. Parish; el primer tomo sobre la Confederación; la revista El Plata, sobre legislación y jurisprudencia, Diccionario castellano de Salvat, Biografía de San Martín, Consideraciones sobre la decadencia del imperio romano, entre otros ejemplares disponibles.

47. La Confederación, No 43, Rosario, 23/09/1854, p.3.

48. Ídem., No 135, Rosario, 05/05/1855, p. 2.

49. Ídem., No 138, Rosario, 15/05/1855, p .3. Precisamente, en la casa del señor Peñaloza cita en la calle San Lorenzo, está ubicada la imprenta de La Confederación, lugar donde además, se reciben las suscripciones del periódico. 
familia procedentes de San Nicolás. ${ }^{50}$ Se podrían multiplicar los ejemplos sobre estos encuentros sociales que se publican en la sección "Noticias y hechos diversos" de la prensa local. Igualmente, se organizan reuniones y bailes a bordo de embarcaciones, oportunamente amarradas en el puerto. ${ }^{51}$

Los registros visuales también documentan las renovadas condiciones de la ciudad: litografías que se incluyen en libros de viaje, croquis, grabados, acuarelas y la incipiente fotografía, posible porque la práctica de daguerrotipo comienza a desplazarse. ${ }^{52}$ De este modo, la cultura artística abre su camino en la vida social. Asimismo, es notable la presencia de profesionales, ingenieros, técnicos, médicos, boticarios, hombres de leyes. Sin embargo se

50. Ídem., No 295, Rosario, 14/06/1856, p. 2.

51. Reunión y baile a bordo del vapor "Primer Argentino" propiedad de accionistas de Rosario. CARRASCO, Eudoro y CARRASCO Gabriel, Anales de la ..., Op. Cit. p. 361.

52. El artista Juan León Palliére deja constancia de su crecimiento a través de un croquis a lápiz del puerto, trazado en 1858, Brayer bosqueja la Vista de Rosario de Santa Fe. Más tarde Thomás Hutchinson, cónsul de Gran Bretaña en Rosario, incluye en su obra Buenos Aires y otras provincias argentinas (1866) tres litografías sobre la ribera del río Paraná realizadas por Tilston. Entre los fotógrafos que transitan por la ciudad en la década '50, se puede mencionar al artista italiano Arístides Sthepani, al pedagogo Amadeo Jacques y a José Bisaño. Estos profesionales migran de una ciudad en otra intentando afianzar un incipiente mercado, en GALASSI, Gisela, "Ciudad y modernidad: Rosario bajo la lente", en FERNANDEZ Sandra (directora) Gritos y susurros. Separatas de historia sociocultural rosarina, Editorial El Ombú Bonsái, Rosario, 2012, pp. 10-17. La Bajada principal del Puerto del Rosario está representada en una acuarela de 1854 de Eudoro Carrasco según CARRASCO Eudoro y CARRASCO Gabriel, Anales de la..., Op. Cit. p. 283. Además, cabe mencionar el grabado de E. Jennings sobre la vista de Rosario desde la barranca entre 1855-1860. aduce que hay pocos hombres de letras. ${ }^{53}$

En este contexto, para sustentar las finanzas del Estado confederal en 1854 se abre el Banco Nacional de la Confederación, proyecto prontamente malogrado; posteriormente se organiza el sistema de mensajerías terrestres; comienzan las obras de construcción del puerto a cargo de "Muelles de Rosario" integrado por los empresarios Hopkins y Esteban Rams y Rubert y en 1857 se inaugura el Banco de Mauá y Compañía ${ }^{54}$ y se instala la primera Bolsa de Comercio fundada por Federico Woodgate. ${ }^{55}$ Así, progresivamente, la ciudad adquiere el aspecto moderno y portuario que le da su impronta.

El viajero chileno Vicuña Mackenna ${ }^{56}$ que llega desde Buenos Aires en 1855 y permanece en Rosario pocos días, deja en sus escritos de viaje notas sobre los asistentes a una representación teatral, así como sobre la estructura de la ciudad que ocupa una veintena de manzanas con tres calles principales lugar de concentración de los principales almacenes semejantes a los bonaerenses. ${ }^{57}$ Cabe destacar que, según la propuesta de Estanislao Zeballos, las primeras nomenclaturas de las calles datan de 1853 pero

53. ALVAREZ, Juan, Historia de Rosario..., Op. Cit, p. 285.

54. Ídem, pp. 262-272.

55. CARRASCO Eudoro y Gabriel, Anales de la ..., Op. Cit., p. 362.

56. Entre los diarios de viajeros que dan cuenta de las características de la sociedad rosarina se encuentran el chileno Benjamín Vicuña Mackenna, Páginas de mi diario, durante tres años de viaje, 1853-1854-1855; William Mc Cann, Viaje a caballo por las provincias argentinas, los escritos de Eudoro y Gabriel Carrasco, Anales de la..., Op.Cit.

57. TARRAGÓ, Griselda, De la orilla ..., Op. Cit., p. 140. 
la costumbre de designarlas por sus nombres es más tardía. ${ }^{58}$

La ciudad y las instituciones públicas se convierten en escenario de intercambios sociales y revelan modificaciones de los "códigos de relación que identifican y definen la esfera pública". ${ }^{59} \mathrm{El}$ conjunto de las nuevas interrelaciones está vinculado al desarrollo de la prensa escrita, de la opinión pública y la libertad de expresión. A diferencia de la porteña que si bien de tirada diversificada no mantiene en su conjunto una periodicidad extensa, la prensa rosarina se destaca por la continuidad de publicación. La Confederación ${ }^{60}$ es la primera publicación periódica de Rosario. Se editan novecientos veintinueve números desde mayo de 1854 a octubre de 1861, inicialmente la edición tiene salida bisemanal, luego se edita los días martes, jueves y sábados. Su fundador y director es Federico de la Barra (1817-1897), personaje de larga trayectoria periodística vinculado a principios progresistas y que aspira a crear conciencia de que la obturación de las libertades individuales y el impacto de la violencia sólo contribuyen a que el pueblo se torne indiferente. ${ }^{61} \mathrm{El}$ primer ejemplar destaca la importancia de

58. CARRASCO Eudoro y CARRASCO Gabriel, Anales de la..., Op. Cit., pp. 269-271.

59. GONZÁLEZ BERNARDO, Pilar, Civilidad y politica..., Op. Cit., pp. 256-257.

60. Sin que signifique priorizar un análisis cuantitativo, el presente trabajo acentúa el análisis de La Confederación tanto por la extensión de la edición (1864-1861) como por la disponibilidad de su corpus completo.

61. BONAUDO, Marta, "De la opinión publicada a la opinión pública. La prensa como lugar de representación y de conflicto" en Bonaudo, Marta (directora) Imaginarios y prácticas de un orden burgués. Rosario, 1850-1930, T. I, Las palabras y las cosas, Editorial Prehistoria, Rosario, 2005 , p. 82. dar un periódico a la ciudad de Rosario, y dotarla de un establecimiento tipográfico ... indispensable en un pueblo que se esfuerza notablemente en su desarrollo, que reclama medios, y que necesita facilidade. ${ }^{62}$

De la Barra interviene en la creación de la Sociedad de Beneficencia; es el primer presidente del Club Social de Rosario fundado en 1873, participa en el proyecto de creación de una Escuela Normal de Profesores de Enseñanza Primaria. Iniciado el año 1855, oportunamente publica una nota escueta en las páginas del periódico dando a conocer que se ve forzado a abandonar la ciudad Rosario ${ }^{63} \mathrm{y}$ por una disposición superior debe viajar a $\mathrm{Pa}-$ raná, comunicando que por el término de dos meses el editor, responsable y encargado será José María Arzac. ${ }^{64}$ Efectivamente, esta decisión responde a una orden recibida de parte del gobernador de Buenos Aires, Pastor Obligado. Según estas indicaciones debe alejarse de la provincia como consecuencia de la defensa de la Confederación que hace el publicista en las páginas del periódico local. Previamente al arribo del periodista a la capital entrerriana, Urquiza recibe peticiones de argentinos y extranjeros residentes en Rosario, en las que se solicita gestione el levantamiento de la disposición por inconstituciona ${ }^{65} \mathrm{y}$ en estas circuns-

62. La Confederación, No 1, Rosario, 25/05/1854, p. 2.

63. "El gefe político y muchas señoras de la Sociedad de Beneficencia le dirigen cartas manifestándole su pesar porque tal orden haya de cumplirse" en CARRASCO Eudoro y CARRASCO, Gabriel, Anales de la..., Op. Cit., p. 315 .

64. La Confederación, № 115, Rosario, 15/03/1855, p. 2.

65. DE MARCO, Miguel Ángel, FISCHER, Ana María, DÍAZ NICOLAU María Cristina, PALLAVICINI Mercedes, Orígenes de la Prensa en Rosario, Edito- 
tancias Santiago Derqui interviene frente al gobernador para resolver la dificultad política del publicista. ${ }^{66}$

Finalizada la publicación de La Confederación, de la Barra colabora con Derqui, luego trabaja como redactor en La Capital hasta 1878, cuando se radica en Buenos Aires para fundar el diario El Siglo. Como periodista apela a la importancia de trabajar "bajo todos los gobiernos y bajo todos los colores locales, porque las disidencias políticas no deben embotar jamás el fervor del progreso". ${ }^{67}$ Estas argumentaciones parecen justificar los escritos adversos al pronunciamiento de Urquiza que redactara con el título "La vida de un traidor" en el Diario de la Tarde de Buenos Aires. ${ }^{68}$ Sin embargo, las deserciones individuales al campo adversario no constituyen la causa más frecuente de los cambios que caracterizan la carrera de los publicistas. Aún considerando la coyuntura de un periodismo que no puede evitar su dependencia financiera de las condiciones oficiales, se debe argüir más en que los zigzagueos de los periodistas responden a que las corrientes políticas de pertenencia están en constante redefinición ${ }^{69}$ y menos en un periodismo que "no tiene opinión propia, independiente y se-

rial Colmegna, Santa Fe, 1969, p. 24.

66. AUZA, Néstor Tomas, El periodismo de la..., Op. Cit., p. 147.

67. MIKIELIEVICH, Wladimir, "La nacionalidad de Federico de la Barra", en Revista de Historia de Rosario, Rosario, 1963, Año 1, № 3, pp. 78-79.

68. DE MARCO, Miguel Ángel, FISCHER, Ana María, DÍAZ NICOLAU, María Cristina, PALLAVICINI Mercedes, Orígenes de la Prensa..., Op. Cit. pp. $14-15$

69. HALPERÍN DONGHI, Tulio, José Hernández..., Op. Cit., p. 24. gura, porque es un cata-viento que se dirige al rumbo hacia donde le impelen las fuerzas de las circunstancias y los apuros de la situación. ${ }^{70}$

En 1856 se imprimen escasos veintidós números de El Comercio, dirigido por Eudoro Carrasco y Manuel Olascoaga y en 1859 aparece sólo por algunos meses El Comercio de Rosario, redactado por Evaristo Carriego y Olegario V. Andrade. En el mismo año, Dalmaceno Fernández y Pedro Nicolorich redac$\tan$ El Litoral. En febrero del siguiente año se inicia la impresión de El Progreso, periódico comercial, político y literario, definición que caracteriza la prensa de la época. Se edita los días lunes, miércoles y viernes, su fundador y redactor es Juan Francisco Monguillot hasta entonces director del periódico porteño $L a$ Prensa, afín a la política urquicista. La publicación de un artículo polémico en este periódico, si se tiene en cuenta que los condicionamientos financieros hacían que la línea política no pudiera ser expuesta en total independencia por su redactor, ${ }^{71}$ motiva la condena a pagar una multa, la inhabilitación temporal de la edición y su destierro de Buenos Aires por declararse en rebeldía con respecto a la causa judicial incoada en su contra. ${ }^{72} \mathrm{Al}$ respecto, $L a$ Confederación informa que no sólo es multado Monguillot sino además Moreno, redactor de la Regeneración y el editor de Fray Supino. ${ }^{73}$

70. FERNÁNDEZ SEBASTIÁN, Javier "Periodismo" en FERNANDEZ SEBASTIÁN, Javier y FUENTES, Juan Francisco (directores) Diccionario político..., Op. Cit., p. 529.

71. HALPERÍN DONGHI, Tulio, José Hernández..., Op. Cit., p. 24.

72. WASSERMAN, Fabio, "La libertad de imprenta..." Op. Cit., p. 144.

73. La Confederación, No 587, Rosario, 19/06/1858, p. 2. 
Con respecto al periódico El Progreso, cuenta posteriormente con la colaboración de Carriego. $^{74}$

Además, en esos tiempos, un "remanso"75 de información está disponible para su lectura en diversas impresiones que entretejen la malla periodística de la Confederación: El Nacional Argentino de Paraná que se inicia en octubre de 1852 y continúa hasta 1860 , se suman el Eco del Litoral, El Mercantil y La Época de Gualeguaychú; El Uruguay de Concepción del Uruguay; El Progresista de Concordia, el Co-

74. El Comercio de Rosario, se edita a la tarde. Es un periódico comercial, político y literario. Se imprime en los talleres de la calle Rioja No 144 de la ciudad de Rosario. Lugar donde se editará inicialmente $E l$ Progreso. Transcurridos los primeros meses, el gobierno de la provincia de Santa Fe solicita a este periódico, la devolución de las instalaciones que oportunamente cede en préstamo. Las oficinas se trasladan a la calle Aduana No 11, y posteriormente funcionan junto a la imprenta en la calle San Lorenzo No 83. Según información que se lee en El Progreso en los № 23, 47 y 213 del 23-04-1860, 20-06-1860 y 25-04-1861 respectivamente.

Las últimas direcciones registradas de los talleres gráficos de La Confederación y El Progreso corresponden respectivamente a calle Santa Fe No 37 y San Lorenzo No 83. Este último taller se remató el 25 de abril de 1862. Funcionará en este lugar, el periódico Nueva Era, mientras en el taller de calle Santa Fe se imprimirá La Patria, ambos periódicos mitrista. Datos suministrados por la Revista de Historia de Rosario, Año 1-No 2, 1963.

75. El vocablo "remanso" es tomado del modelo de la cascada formulado por Kart Deutsch (1912-1992) en Análisis de las relaciones internacionales. En esta obra el autor explica la formación de opiniones que fluyen desde arriba hacia abajo por una serie de remansos. El lugar más elevado en la cascada escalonada lo constituyen las elites económicas y sociales, continúan las políticas y gubernamentales, los medios de comunicación, los líderes de opinión y por último, el público. Los procesos de formación de opinión se modifican horizontalmente por las interacciones intrarremansos. Citado por SARTORI, Giovanni, Teoría de la..., Op. Cit., pp. 126-127. mercio de Corrientes, entre otros. ${ }^{76}$ Es decir, a fines de la década, los lectores tenían acceso a publicaciones locales diarias, sumadas a las que circulan en la región, accesibilidad y circulación que indicarían que el público se expande y se mantiene informado sobre los acontecimientos rioplatenses y los principales sucesos de otros países.

\section{El perfil polémico de los periódicos rosarinos}

Con respecto a La Confederación, desde los primeros números de su edición, se leen informes sobre movimientos de fuerzas navales, noticias internacionales, llegada de delegados extranjeros, mediaciones amistosas, conflictos internos, publicaciones de tratados de amistad, comercio y navegación y otro tipo de documentación oficial de conocimiento público que anuncia:

el progreso rápido que en el sentido material se verifica en la Confederación, el aumento de transacciones mercantiles con el extranjero, provocarán naturalmente nuevos tratados y relaciones con el mundo... con pueblos cultos y productores. ${ }^{77}$

La Confederación, somete a autoanálisis su propia actividad y como exponente local se considera el portavoz de un gobierno legítimo que instaura la participación e interpreta que es capaz de ejercer la plena libertad de impren-

76. AUZA Néstor Tomas, El periodismo de la..., Op. Cit., ofrece al lector un listado significativo de los periódicos de las trece provincias confederadas y el análisis sobre algunos órganos de prensa, otorgando información sobre sus redactores, características de los periódicos, cuestiones económicas y políticas que atañen a sus ediciones.

77. La Confederación, No 58, Rosario, 20/10/1854, p. 3. 
ta porque "todo habitante de la Confederación puede publicar sus ideas por la prensa sin censura previa"78 según las nuevas ideas y los principios constitucionales, enunciado que "parecía sugerir que más que servir exclusivamente a una ciudad, ambicionaba reflejar el sistema político iniciado con esa Constitución". ${ }^{79}$ Mientras su punto de partida es la "pelea por la libertad, por las instituciones y por el desarrollo material e inteligente de estas regiones fecundas", ${ }^{80}$ prepara los ánimos para con otros gobiernos aduciendo que el cauce de otros periódicos se sujeta a restricciones impuestas por aquellos Estados que pretenden compatibilizar censura y progreso.

En esta dirección, aunque los temas internacionales son materia alejada de la preocupación habitual del hombre común, pueden provocar cierto interés cuando se reiteran frecuentemente. Tal las reiteradas diatribas sobre las acciones del gobierno paraguayo que "obstaculiza" los fines benéficos y formativos de la libertad de prensa cuando temporalmente toma medidas coerci-tivas sancionando la circulación de periódicos, medidas que apelan no tanto a razones morales como al nuevo ideario. En Paraguay, la prensa está limitada a un único periódico, El Semanario, de tiraje semanal en todo el territorio y cuando algunos ejemplares llegan a manos de los lectores de la Confederación, en ocasión de expresar opiniones antagónicas con la prensa local, o verter críticas a ciertos personajes, la prensa paraguaya es calificada oportunamente de mediocre y sin am-

78. La primera parte del artículo 14 de la Constitución Nacional se transcribe en la parte superior de cada número de La Confederación.

79. AUZA Néstor Tomás, El periodismo de la..., Op. Cit., p.141.

80. La Confederación, № 1, Rosario, 25/05/1854, p. 2. plitud de criterios "tal el gobierno que representa”. En este contexto, De la Barra parece dar su versión más racionalizada cuando enuncia que "al pisar... la arena política no entramos armados ni de esos dardos envenenados por la pasión, ni manchados por el egoísmo". ${ }^{81}$ Sin embargo, el periodista tiene una mirada distraída cuando ciertas palabras punzan las hojas impresas: "medidas egoístas", "gobierno despótico que adiestra masas", "gobierno depravado, desmoralizante", "incapacidad del Sr. López" que "hace pasar a su país como una tribu" que lo reduce a "una gran masa destituida de todo derecho político", es posible por "la tolerancia que le acuerda la civilización que rodea sus fronteras". Estas connotaciones contrastan con otras exiguas valoraciones que oportunamente atenúan las hostilidades y recuperan la imagen y motivan el "aplauso al gobierno paraguayo", en circunstancias que favorecen a la Confederación Argentina. Asimismo, el gobierno confederal establece ciertos mecanismos preventivos frente a aquellas críticas consideradas abusivas $^{82}$ y alerta al público lector sobre las particularidades del periódico paraguayo "adulador del presidente y su familia" que tiene "la fidelidad del perro al amo". ${ }^{83}$

La prensa escrita como esfera pública de la política, lejos de considerar que en la política

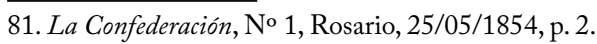

82. WASSERMAN, Fabio, "La libertad de imprenta...", Op. Cit., p. 134. En este artículo, el autor examina el carácter sistemático de los límites de la libertad de imprenta en Buenos Aires en la década de 1850, considerando tanto las normativas, mecanismos de cooptación o persecución para llevar a cabo el control sobre la prensa. Otro ejemplo es el ensayo de PICCATO, Pablo, "Jurados de imprenta en México: el honor en la construcción de la esfera pública, 1820-1882" en ALONSO Paula (compiladora) Construcciones impresas..., Op. Cit.

83. La Confederación, № 219, Rosario, 29/11/1855, p. 2. 
no existen verdades absolutas, reprueba las declaraciones o comentarios de la oposición. Exceptuando eventuales comentarios enunciados bajo una luz más favorable, según se menciona anteriormente, el listado de agravios que señala la asimetría entre los gobiernos de los dos países acentúa la impronta de progreso y las ventajas de la libre expresión y de la opinión de los periódicos confederales, en particular de La Confederación. Estas prácticas discursivas encuentran significado en su entorno y en el ejercicio de la libertad de expresión que abre camino ante sus oponentes para legitimar sus posiciones políticas, agudizando las problemáticas vigentes. Explicar cada una de las circunstancias que ocasionan comentarios adversos, exceden la propuesta de este artículo. Sin embargo interesa subrayar la coyuntura conflictiva entre la Confederación y Paraguay, y esta República con el Imperio de Brasil, ocasionada fundamentalmente por desacuerdos sobre la navegación del río Paraná y sus afluentes y sobre la definición de límites territoriales, cuestiones que anuncian la "maldita guerra" en referencia a la Guerra del Paraguay.

Desde el inicio de su publicación, La Confederación atestigua un rol central crítico hacia la oposición gubernamental de Buenos Aires, ciudad que "está librada á un camino tan incierto y cuyo porvenir está envuelto aun entre celajes después de tanto sufrimiento..." ${ }^{84} \mathrm{El}$ redactor explica en una nota titulada "Aislamiento y Constitución”, nota que continúa en números siguientes, las implicancias de la separación de Buenos Aires que "presupone causa para interrumpir el orden nacional y colectivo de la administración general de un Estado... aislamiento que es la segregación de

84. La Confederación, № 1, Rosario, 25/05/1854, p. 3. una fracción”. ${ }^{85}$

El perfil polémico, combatiente y el lenguaje licencioso para calificar tanto al gobierno paraguayo como al porteño se anuncia en el contenido de una correspondencia enviada por de la Barra a Urquiza, unos meses más tarde iniciada la publicación del periódico, donde el periodista aclara:

la cuestión de Buenos Aires he comenzado a tratarla con la altura que merece porque el lenguaje de nuestra hoja debe ser digno en la forma y fuerte en el fondo... y en el exterior se haga el contraste con la prensa enemiga. ${ }^{86}$

En 1857, afirmando el combate de plumas de un periodismo oficioso, se edita un conjunto de fascículos titulados "La dictadura" dirigidos contra el gobierno de Valentín Alsina ${ }^{87}$ La prensa rosarina no sólo califica a las fuerzas gubernativas porteñas, "gobierno de compadritos... que agotan los elementos que se brindan á la prosperidad de Buenos Aires", gobierno caracterizado por "la prepotencia funesta" 88 sino además califica a la prensa porteña cuando con cierta ironía en la construcción del discurso, refiere al comentario sobre la entrada de indios y el arrebato de ganado, en tales circunstancias enuncia "Brava la defensa de la frontera! A quien echarán ahora la culpa los diaristas porteños?, Les mandamos de aquí esas visitas?" 89

85. La Confederación, No 3, Rosario, 03/06/1854, p. 2.

86. AUZÁ Néstor Tomas, El periodismo de la..., Op. Cit., p. 143. Carta del 10 de junio de 1854.

87. Ídem, p. 146.

88. La Confederación, № 595, Rosario, 13/07/1858, p. 2.

89. Ídem., No 596, Rosario, 15/07/1858, p. 2. 
De igual modo, el Comercio de Rosario, denuncia la corrupción en manejos de los fondos de la Aduana ${ }^{90}$ y además, en una nota cita al Nacional y la Tribuna como aquellos periódicos que representan los intereses del gobierno liberal y coartan la libertad de pensamiento, "es la prensa de Buenos Aires el retrato... de su triste situación, la prueba más palpable y evidente del despotismo... que constituyen la base del actual gobierno". ${ }^{91}$ Por ello, la Reforma Pacífica y L'a Unión Etrangere, ejemplos de órganos imparciales que están circulando, serán pronto sofocados por la intolerancia de la prensa de Buenos Aires, que carece de la virtualidad crítica.

El curso de los acontecimientos se puede leer en otros periódicos de la región: El Imparcial de Córdoba; El Nacional y Los Debates de Buenos Aires, El Nacional Argentino de Paraná y El Patriota de Santa Fe. Mientras en las páginas de El Progreso, en momentos que se integra Evaristo Carriego ${ }^{92}$ a la redacción del mismo, en una nota titulada "Nuestros propósitos" comenta que "venimos a la prensa con el ánimo de propagar en ella las sanas doctrinas sin las cuales no hay grandeza ni progreso verdadero.” Más allá de estas sensatas considera-

90. Comercio de Rosario, No 31, Rosario, 28/03/1859, p. 2.

91. Ídem, № 55, Rosario, 27/05/1859, p. 2.

92. Evaristo Carriego (1838-1908), entrerriano, doctorado en Jurisprudencia en Córdoba en 1856. Durante su estadía en Rosario ejerce como periodista y abogado.

Luego en las ciudades de Entre Ríos, Buenos Aires y Córdoba ejerce exclusivamente su labor periodística. Redactor de La Patria Argentina y El Litoral, ambos periódicos de Paraná; La Política (1872), Los Castigos (1877), Las Provincias (1881) y Los Tiempos (1885) editados en Buenos Aires; El Interior y La Constitución editados en Córdoba. Citado por DE MARCO, Miguel Ángel, FISCHER, Ana María, DÍAZ NICOLAU, María Cristina, PALLAVICINI Mercedes, Orígenes..., Op. Cit., pp. 40-41. ciones, en sus páginas no faltan las polémicas con el gobierno porteño. Sin embargo, en uno de sus números se lee la transcripción de una nota del Nacional donde se agradece a Carriego "escritor ilustrado de Rosario, la imparcial apreciación que de nuestros hombres y cosas hace en El Progreso". ${ }^{93}$ Con anterioridad, el gobierno de la provincia de Santa Fe solicita al director del periódico, la devolución de las instalaciones donde funcionan los talleres gráficos del mismo y que oportunamente las autoridades provinciales ceden en préstamo. ${ }^{94}$ Este pedido, es comentado en El Progreso aduciendo desconocer los motivos del reclamo y al parecer, la situación genera cierta tensión porque pone en duda la posibilidad de continuidad de la impresión.

Ciertamente, el ideario político decimonónico tiene estrecha correspondencia con la prensa escrita y el interés en comunicar los asuntos públicos. Esta relación permite la construcción de lazos que unen a los individuos con el cuerpo político y de esta manera, el público y la opinión, juegan un rol importante como fuente de legitimidad política. Ahora bien, parafraseando a Anthony Giddens, si se entiende que "todos los actores sociales existen en contextos situados en el interior de segmentos de espacio-tiempo, lo novedoso para algunos de esos actores no lo será para otros", ${ }^{55}$ tanto por "los hiatos de información" no sólo en espacios alejados de la urbanidad

93. El Progreso, No 37, Rosario, 28/05/1860, p. 3.

94. Ídem., № 23, Rosario, 23/04/1860, p.2. Las oficinas del periódico son trasladadas a la calle Aduana No 11 y posteriormente funcionan junto con la imprenta en la calle San Lorenzo No 83.

95. GIDDENS, Anthony, La constitución de la sociedad. Bases para la teoría de la estructuración, Editorial Amorrortu, Buenos Aires, 2006, p. 357. 
sino en aquellos segmentos sociales limitados en cuanto a oportunidades educacionales y de alfabetización.

He aquí entonces la pregunta sobre el alcance de la opinión pública en la ciudad de Rosario. La amplitud del arco temático abordado por los periódicos locales supone un público lector diverso, la variación de tirajes de las ediciones que oscilan entre doscientos y quinientos ejemplares estarían indicando el probable incremento de lectores. Según la citada correspondencia de F. de la Barra, La Confederación tiene ciento cuarenta suscriptores pagos y se reparten doscientos números entre Montevideo, Buenos Aires y su campaña y las provincias del interior. ${ }^{96}$ Además de la Barra, en un acertado comentario, afirma que el diario no es "el único y exclusivo órgano de opinión y de las necesidades de todos". ${ }^{97}$ Para entonces, y dando por ciertas las cifras antes mencionadas, un análisis que relacione producción de prensa local, ediciones que circulan, suscripciones, cantidad de lectores y población, es difícil de documentar teniendo en cuenta que el Primer Censo de la Provincia Santa Fe data recién de 1858, registrando para el departamento Rosario 22.492 habitantes, de los cuales 19.225 tenían menos de cuarenta años. ${ }^{98}$ En cuanto a los extranjeros, cuyo número total es de 978 personas, 836 son italianos. ${ }^{99}$

Si bien existen evidencias sobre las características socioculturales de la población, resulta dificultoso investigar la incidencia de la

96. AUZA, Néstor Tomás, El periodismo de la..., Op. Cit., p. 144.

97. La Confederación, No 94, Rosario, 23/01/1855, p. 3.

98. TARRAGÓ, Griselda, De la orilla del..., Op. Cit., p. 139.

99. Ídem, p. 146. prensa escrita sobre la opinión, no solo por la insuficiencia de la documentación sino además porque los periódicos no son los únicos medios de comunicación, debate y generadores de opinión, según afirma de la Barra. Por cierto, circulan libros, folletos, pasquines y otro tipo de impresos, incluso la transmisión verbal de las opiniones tienen un papel fundamental porque la difusión de la opinión en el siglo XIX continúa siendo un hecho colectivo. ${ }^{100}$ Además, es necesario tener en cuenta si la gran masa -aún considerando que no es totalmente iletradadispone de medios económicos para adquirir periódicos u otro tipo de literatura. Al modelo de racionalización según el proyecto civilizador acuñado por Andrés Bello y Domingo F. Sarmiento es posible incorporar la cuestión del "otro". En este proceso, adquiere preponderancia el mediador, especie de educador que lee el periódico para los sectores analfabetos de la sociedad, reforzando algunas noticias que circulan de boca en boca. ${ }^{101} \mathrm{La}$ existencia de mediadores en el medio rosarino, posibilita incorporar la cultura escrita a quienes no sabían leer ni escribir y si bien esta modalidad no disuelve en su totalidad las fronteras que separa a los lectores y a los que no lo son, la lectura en voz alta y su escucha, más la circulación cotidiana de la prensa amplían el público "lector" tanto para informarse como para intercambiar opiniones sobre los hechos que están sucediendo.

\section{A modo de conclusión}

Como se expresa en el trabajo, considerando tanto los registros escritos como los

100. GONZÁLEZ BERNALDO, Pilar, Civilidad y politica...,Op. Cit., p. 176.

101. LETTIERI, Alberto, La construcción..., Op. Cit., p. 259. 
visuales, inicialmente la ciudad transmite una imagen rudimentaria donde los lugares de propagación de la opinión pública se construyen -como se lee en La Confederación- al compás del vértigo de la modernización que trasforma el villorio en ciudad. Este ritmo de progreso permite la materialidad, pluralidad y circulación creciente de publicaciones periódicas, folletines, pasquines, revistas, libros y otros escritos. Estas condiciones se asocian tanto a la emergencia de un importante núcleo urbanístico moderno como al impulso dado por los intereses del gobierno urquicista que promueve y sostiene con la colaboración de escritores itinerantes, publicaciones oficiales en las diversas provincias construyendo una "red periodística" de la cual las publicaciones rosarinas forman parte. Un primer balance muestra que la prensa rosarina de mediados del diecinueve responde a la trama de intereses confederales y al perfil polémico que caracteriza al periodismo de esa época interesado en resaltar los conflictos que sacuden el ámbito político.

Los periódicos publicados en Rosario, $L a$ Confederación y, en menor medida, El Progreso, El Comercio y el Comercio de Rosario, son partícipes de la vida social y comercial de la ciudad y de la región. La población rosarina inmersa en profundas transformaciones -cuyas capas lectoras se supone son cada vez más ampliasestá adoptando una conducta racionalmente orientada a la información que le brindan los periódicos en circulación, medios de difusión que se erigen en importantes instrumentos políticos del gobierno confederal. El contenido de sus páginas excede lo meramente informativo y adquiere protagonismo en las polémicas políticas más significativas que atañen a las coyunturas por las que atraviesa la Confederación. Esta escritura pública -embretada con los intereses del gobierno al cual responde- no descansa en un "juego limpio" y la libertad del decir pone en escena el alcance y el nivel de los debates que incumben a las instituciones gubernamentales implicadas en los conflictos. Precisamente las palabras licenciosas utilizadas para dar cuenta de las distintas coyunturas políticas, con pigmentos irónicos o agraviantes, siembran el camino que conduce al enfrentamiento de la Confederación y el Estado de Buenos Aires y anuncian el posterior desencadenamiento de la Guerra del Paraguay.

Cabe aquí la referencia al epígrafe de este trabajo. El sentido de algunas palabras que se escriben en los periódicos en gran medida está condicionado por las circunstancias de emisión así como las de recepción por el público lector y oyente. Palabras emitidas en un clima político agitado y para un público, el rosarino, que no deja de estar influido por los vaivenes de la política facciosa preocupada, en última instancia, por definir el rumbo del futuro país y al mismo tiempo, a través de la prensa local, el gobierno confederal pretende construir su propia imagen para diferenciarse del perfil de los gobiernos porteño y paraguayo.

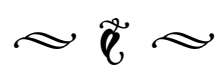

Recibido: 02/08/2013 Aceptado: 28/05/2014 